\title{
Mesolamellar composite of TiN and CTAB using fluoride ion bridge: synthesis, mechanism \& characterization
}

\author{
Tumbavanam Venkateswaran Anuradha
}

Department of Materials Engineering, Indian Institute of Science, Bangalore, India; anu guhan@yahoo.co.in

Received 29 December 2009; revised 10 February 2010; accepted 5 March 2010.

\begin{abstract}
In an attempt to synthesize hexagonal mesoporous titanium nitride, a mesolamellar composite based on titanium nitride and cetyltrimethylammonium bromide (CTAB) is obtained by the sol-gel route involving templating at $80^{\circ} \mathrm{C}$. The mechanism underlying the above synthesis is discussed for the first time in the literature and till date there are no reports on the synthesis of mesoporous nitrides. The above mesolamellar composite is found to form an oxide of titania (anatase) upon heat treatment at $335^{\circ} \mathrm{C}$ for $1 \mathrm{~h}$.
\end{abstract}

Keywords: Mesolamellar; Templating; Sol-Gel Method; XRD; FT-IR; SEM

\section{INTRODUCTION}

Mesoporous materials are generally produced by the templating approach using various surfactant species as template. The template acts like an imprint molecule which could then be extracted by either calcination or solvent extraction leaving behind pores in the regions where they are present. At the first critical micelle concentration $(\mathrm{cmc} 1)$, the surfactant species forms self-assembled aggregates with a spherical shape which changes to a rod shape on further increase in the concentration of the surfactant species $(\mathrm{cmc} 2)$. Different liquid crystalline phases with cubic, hexagonal and lamellar structures are formed by further increase in the concentration of the surfactant species (above $\mathrm{cmc} 2$ ) which indeed acts as the template for the production of mesoporous materials.

There are a few reports based on the synthesis of mesolamellar phases based on zirconia [1] and silica [2]. Certain species like $\mathrm{F}^{-}$ions and acetylacetone are found to favour the formation of lamellar phases when present in the reaction medium $[3,4]$. There are no reports on the synthesis of mesoporous materials based on TiN due to the non-availability of suitable metal-organic precursor that could be used for the sol-gel synthesis. The precur- sors of TiN are also found to be highly oxophilic and hence there is always a possibility that they will result in the formation of oxynitrides rather than pure nitrides. The present experiments involved the formation of a mesolamellar composite based on TiN and CTAB in the medium enriched with $\mathrm{F}^{-}$ions by sol-gel route at $80^{\circ} \mathrm{C}$. The mechanism underlying the above synthesis is discussed in this communication in more detail for the first time in the literature.

\section{EXPERIMENTAL PROCEDURES}

$2 \mathrm{~g}$ of TiN, $2 \mathrm{~g}$ of CTAB, $25 \mathrm{cc}$ of $\mathrm{HF}-\mathrm{HNO}_{3}$ mixture and $25 \mathrm{cc}$ of distilled water were taken. TiN is dissolved in $1: 1$ solution of $\mathrm{HF}^{-\mathrm{HNO}_{3}}$ mixture $(9: 1)$ in water forming species like $\left[\mathrm{Ti}_{1-\mathrm{x}} \mathrm{F}_{\mathrm{x}} \mathrm{N}_{\mathrm{y}}\right]^{3 \mathrm{n}+}$ to which an aqueous solution of CTAB is added to result in the yellow colored solution which is kept in the oven for $3 \mathrm{~h}$ at $80^{\circ} \mathrm{C}$ and then it is kept aside at RT for $24 \mathrm{~h}$. The yellow solid thus obtained has the composition [CTA] $\left(\mathrm{H}_{2} \mathrm{O}\right)_{\mathrm{n}}\left[\mathrm{Ti}_{1-\mathrm{x}}\right.$ $\left.\mathrm{F}_{\mathrm{x}} \mathrm{N}_{\mathrm{y}}\right]$. Thus a mesolamellar composite based on TiN and $\mathrm{CTAB}$ is formed with the $\mathrm{F}^{-}$ion acting as the bridge between them. The lamellar composite obtained above is characterized by $\mathrm{x}$-ray diffraction (XRD) and FT-IR spectroscopy.

JEOL diffractometer (reflection type-model 8030) is used for the characterization of the materials by $\mathrm{x}$-ray diffraction (XRD). $\mathrm{Cu}$ target is used. A voltage of $30 \mathrm{kV}$, a current of $20 \mathrm{~mA}$, and a step angle of $0.020^{\circ}$ with detection times of $0.5 \mathrm{sec}$ at each step are used. A JEOL 2000FX-IItransmission electron microscope operating at the accelerating voltage of $200 \mathrm{kV}$ is used for TEM studies. The powder samples are crushed thoroughly and dispersed in a suitable organic solvent (acetone or high purity ethanol/methanol) and subjected to ultrasonication before supporting on the carbon-coated grids for loading in the TEM equipment. FT-IR studies are carried out using Perkin Elmer FT-IR equipment. Differential Scanning Calorimetry (DSC) is performed with a Perkin Elmer DSC-2C calorimeter to study the thermal stability of the material. The measurements are carried out under dynamic argon flow condition. Before starting the ex- 
periment the base line was corrected and the calibration of the instrument is done using pure indium. A heating rate of $20 \mathrm{~K} / \mathrm{min}$ is used.

\section{RESULTS \& DISCUSSION}

Porous materials i.e. materials with non-lamellar mesostructures that are stable enough to be preserved after the removal of the structure-directing amphiphile could only be synthesized under aqueous conditions with the utilization of cationic surfactants $[5,6]$ and the other attempts yielded lamellar phases only [7,8]. It is believed that a larger variety of surfactants in the alcoholic medium with a small quantity of water would result in the formation of non-lamellar materials [9]. But the utilisation of alcoholic medium is avoided in this investigation since a highly acidic medium is required for the dissolution of titanium nitride. The only constraint in not making use of the alcoholic medium for the synthesis is the non-availability of a suitable organo-metallic precursor for titanium nitride. There are continuous efforts to synthesize mesoporous materials based on nitrides like silicon nitride for the catalytic applications $[10,11]$ which involves the ammonolysis of $\mathrm{SiCl}_{4}$ in organic solvent. But the handling of halides of titanium like $\mathrm{TiCl}_{4}$ or the organo-metallic precursor like $\left(\mathrm{TiCl}_{4} \mathrm{~L}_{2}\right)$ (where $\mathrm{L}=$ ether, amine and pyridine) is very difficult at room temperature since they are both air-sensitive and moisture sensitive.

Figure 1 shows the XRD of the mesolamellar composite after templating TiN onto CTAB using $\mathrm{F}^{-}$ion as the bridge at $80^{\circ} \mathrm{C}$. The lamellar nature of the composite is confirmed by XRD studies which is again reconfirmed using SEM studies [12,13]. The lamellar nature is found to be accompanied by atomic scale ordering and registry of the layers [14] where the first peak has appeared at $\mathrm{d}$ $\approx 19.4 \mathrm{~A}^{\mathrm{o}}$ with the following peaks at $\mathrm{d} \approx\left\{19.4 / 2 \mathrm{~A}^{\mathrm{o}}\right.$, $19.4 / 3 \mathrm{~A}^{\mathrm{o}}, 19.4 / 4 \mathrm{~A}^{\circ}$ ). The clearly resolved six orders of the diffraction peak as well as the plain baseline in the $20-30^{\circ} 2 \theta$ range suggest that the TiN layers sandwiched between the surfactants are well crystallized as in the case of lamellar $\mathrm{TiO}_{2}$ mesophase which was produced by Lin et al. [15] using CTAB as the templating surfactant for tetrabutylorthotitanate (precursor of $\mathrm{TiO}_{2}$ ) under basic conditions. This high degree of condensation of the inorganic building units may be different from those of the silicate $[16,17]$ and aluminophosphate phase mesophases [18,19] whose frameworks are amorphous in nature. The reflections present in the higher $2 \theta$ region are found to represent the internal structure involving the organization of the lamellae and thus could not be indexed to any impurities, but they could be indexed to an orthorhombic cell with a reasonable justification and this result compares very well with the mesocomposite of zinc phosphate produced by Huo et al. [20].
Figure 2 gives the FT-IR spectra of CTAB and mesocomposite respectively. FT-IR studies of the composite material showed many of the vibration modes like $\mathrm{C}-\mathrm{H} \&$ $\mathrm{C}-\mathrm{N}$ stretching and $\mathrm{C}-\mathrm{H}$ bending similar to that of the template i.e. CTAB which is used as standard for comparison, but the peaks had significantly different intensities and line widths in this case and there are some additional peaks which could be assumed to be due to the transition metal co-ordination with the template. FT-IR studies clearly indicated the formation of composite where CTAB is intact. The peaks appeared at $3651 \mathrm{~cm}^{-1}$ and $3587 \mathrm{~cm}^{-1}$ corresponding to the $\mathrm{O}-\mathrm{H}$ stretching frequencies in the physisorbed water molecules and also the peak at $1627 \mathrm{~cm}^{-1}$ corresponds to the bending mode associated with the physisorbed water molecules.

Differential Scanning Calorimetric (DSC) analysis indicated the decomposition behaviour of the lamellar

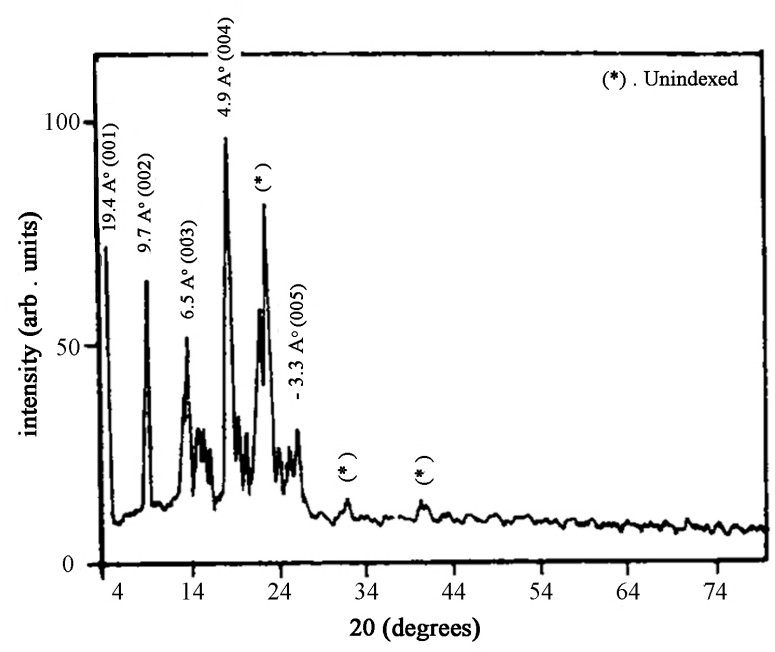

Figure 1. XRD of the mesolamellar composite of TiN and CTAB after templating at $80^{\circ} \mathrm{C}$.

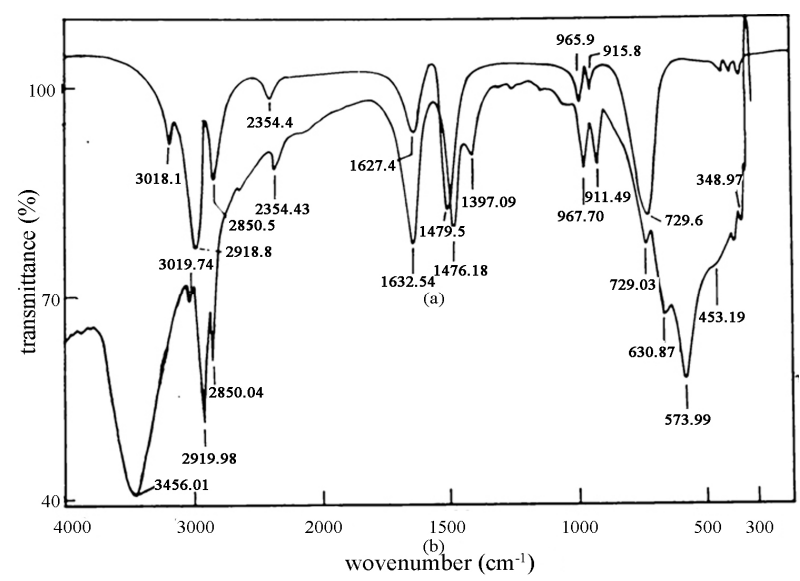

Figure 2. FT-IR spectrum of (a) CTAB; (b) mesolamellar composite of TiN and CTAB. 
composite with three distinct stages of reaction. Figure 3 gives the 'DSC' trace of the mesolamellar composite in argon atmosphere [12] The first split peak (endothermic) around $100^{\circ} \mathrm{C}$ is due to the desorption of water indicating the presence of two different kinds of water molecules associated with the mesocomposite structure namely, water of hydration and associated (hydrogen bonded) water. The second peak at $335^{\circ} \mathrm{C}$, which is exothermic in nature, indicates the decomposition of the organic surfactant. But the appearance of the last two peaks at $391{ }^{\circ} \mathrm{C}$ and $500^{\circ} \mathrm{C}$ is not completely understood. The XRD patterns of the mesocomposite after heating it at $335^{\circ} \mathrm{C}, 391^{\circ} \mathrm{C}$ and $500^{\circ} \mathrm{C}$ for $1 \mathrm{~h}$, are shown in Figure 4. They indicated the formation of anatase form of nanocrystalline titania $\left(\mathrm{TiO}_{2}\right)$ at all the above temperatures and average crystallite sizes less than $10 \mathrm{~nm}$. Figure 5 gives the bright field TEM image of anatase after heat treatment at $335^{\circ} \mathrm{C}$ for $1 \mathrm{~h}$, with its selected area electron diffraction pattern and Figure 6 shows its corresponding dark field TEM image. The dark field TEM image indicated the presence of particles less than $10 \mathrm{~nm}$ though agglomeration is also present.

Intercalated structure is indicated by TEM studies with the average particle size less than $10 \mathrm{~nm}$ [11] which in turn is composed of $\left[\mathrm{Ti}_{1-\mathrm{x}} \mathrm{F}_{\mathrm{x}} \mathrm{N}_{\mathrm{y}}\right]^{3 \mathrm{n}+}$ and $[\mathrm{CTA}]^{+}$with the bridging $\mathrm{F}^{-}$ions. Hence it could be assumed that the $\mathrm{F}^{-}$ion acts as bridge between positively charged $\left[\mathrm{Ti}_{1-\mathrm{x}} \mathrm{F}_{\mathrm{x}} \mathrm{N}_{\mathrm{y}}\right]^{3 \mathrm{n}+}$ and $[\mathrm{CTA}]^{+}$species. The bilayers of CTAB between the layers of TiN are assumed to be interdigited since it is believed that hydrated $\left[\mathrm{Ti}_{1-\mathrm{x}} \mathrm{F}_{\mathrm{x}} \mathrm{N}_{\mathrm{y}}\right]^{3 \mathrm{n}+}$ species is large and thus interdigitation of the surfactant tails allows the surfactant headgroups to be spaced well apart which compares well with the earlier report on iron oxide/surfactant composites [14] where the change in lamellar ' $d$ ' spacing with surfactant carbon chain length for hydrated and dehydrated Fe(II) ions are studied. Figure 7 demonstrates the mechanism underlying the synthesis of lamellar mesophase based on TiN which is found to follow the counter ion (here $\mathrm{F}^{-}$ion) mediated pathway in Liquid Crystal Templating (LCT) approach. Titania is found to be stable in rutile form when the particle size exceeds $14 \mathrm{~nm}$ and below this critical size, anatase phase is stable [21]. Titania obtained by the heat treatment of the mesolamellar composite of titanium nitride fluoride and $\mathrm{CTAB}$ at $335^{\circ} \mathrm{C}$ for $1 \mathrm{~h}$ is found to be anatase with the average particle size less than $\sim 10 \mathrm{~nm}$.

\section{CONCLUSIONS}

There are no reports on the synthesis of mesostructured nitrides till date in the literature and thus it is most remarkable to produce the nanostructured mesolamellar composite of titanium nitride fluoride and CTAB with an average particle size less than $\sim 10 \mathrm{~nm}$ by templating TiN onto CTAB in the highly acidic medium enriched with $\mathrm{F}^{-}$ions $(\mathrm{pH} \sim 2)$ at $80^{\circ} \mathrm{C}$. The interlamellar spacing is found to be $\sim 19 \mathrm{~A}^{\circ}$. The mechanism underlying the above synthesis is also discussed for the first time where $\mathrm{F}^{-}$ions act as the bridge between positively charged $\left[\mathrm{Ti}_{1-\mathrm{x}} \mathrm{F}_{\mathrm{x}} \mathrm{N}_{\mathrm{y}}\right]^{3 \mathrm{n}+}$ and $[\mathrm{CTA}]^{+}$species. The bilayers of CTAB between the layers of TiN are interdigited since that hydrated $\left[\mathrm{Ti}_{1-\mathrm{x}} \mathrm{F}_{\mathrm{x}} \mathrm{N}_{\mathrm{y}}\right]^{3 \mathrm{n}+}$ species are large and thus

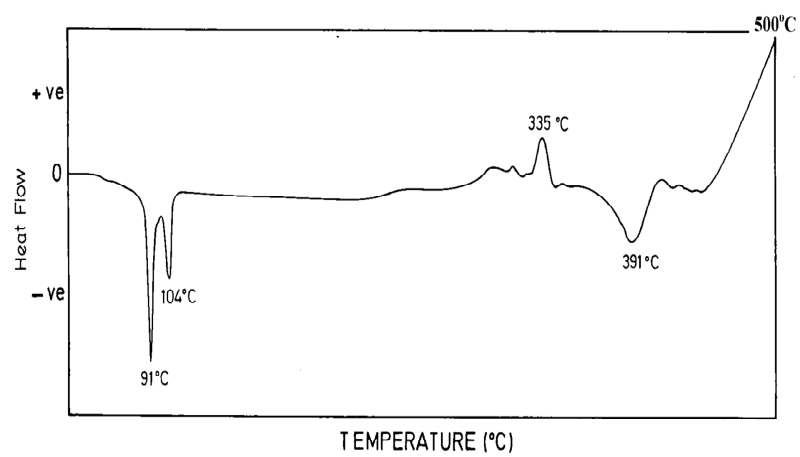

Figure 3. DSC trace of the mesolamellar composite of TiN and CTAB.

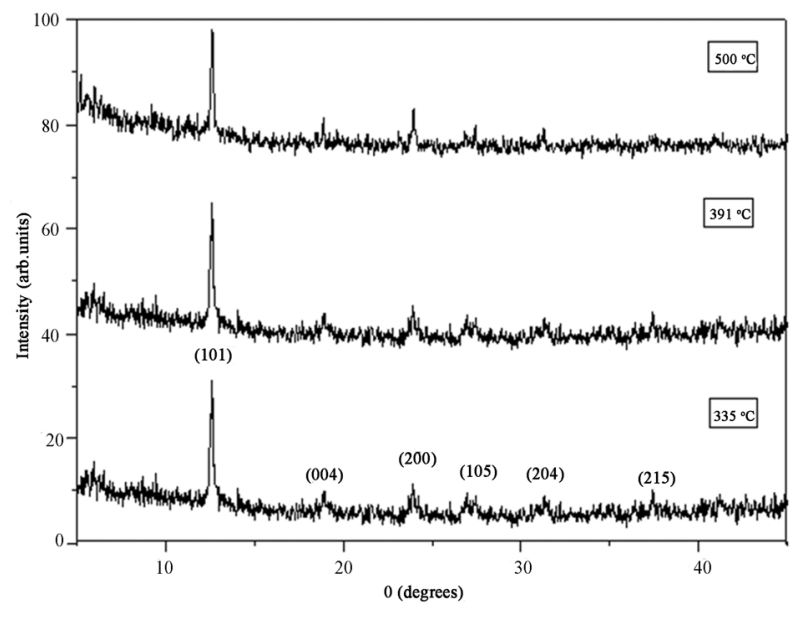

Figure 4. $\mathrm{XRD}$ pattern of the mesocomposite of $\mathrm{TiN}$ and $\mathrm{CTAB}$, after heat treatment at (a) $335^{\circ} \mathrm{C}$; (b) $391^{\circ} \mathrm{C}$; (c) $500^{\circ} \mathrm{C}$, for $1 \mathrm{~h}$.
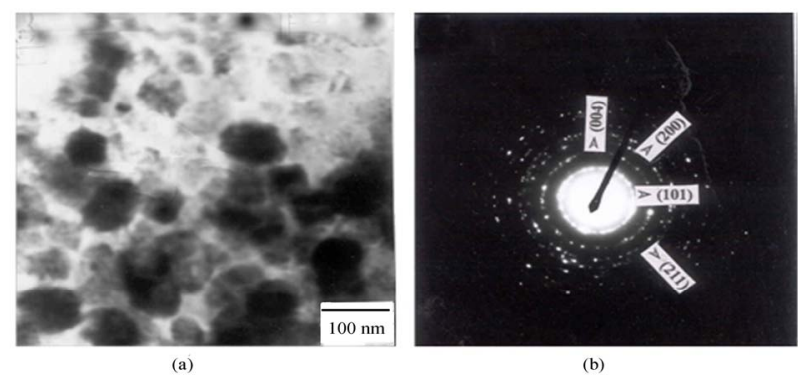

Figure 5. (a) The bright field TEM image of $\mathrm{TiO}_{2}$ (anatase) obtained from the mesolamellar composite after heat treatment at $335^{\circ} \mathrm{C}$ for $1 \mathrm{~h}$, and (b) its corresponding selected area electron diffraction pattern. 


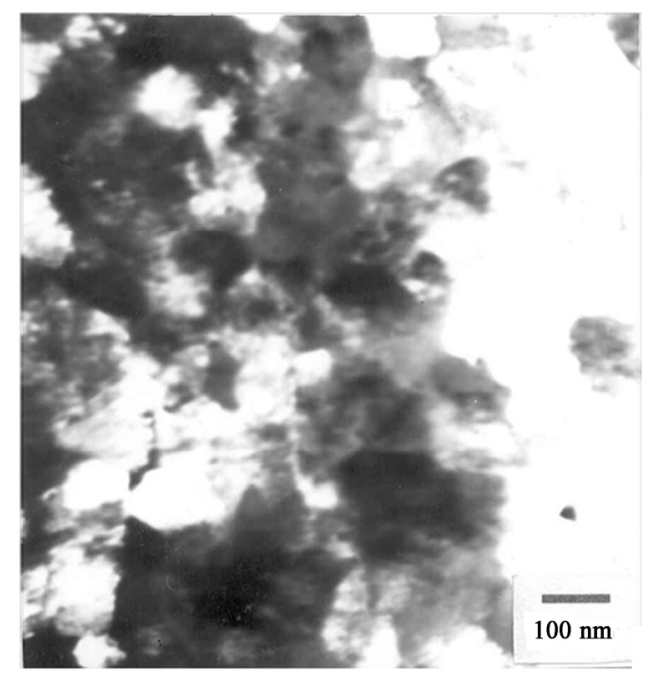

Figure 6. The dark field TEM image of $\mathrm{TiO}_{2}$ (anatase) obtained from the mesolamellar composite after heat treatment at $335^{\circ} \mathrm{C}$ for $1 \mathrm{~h}$.

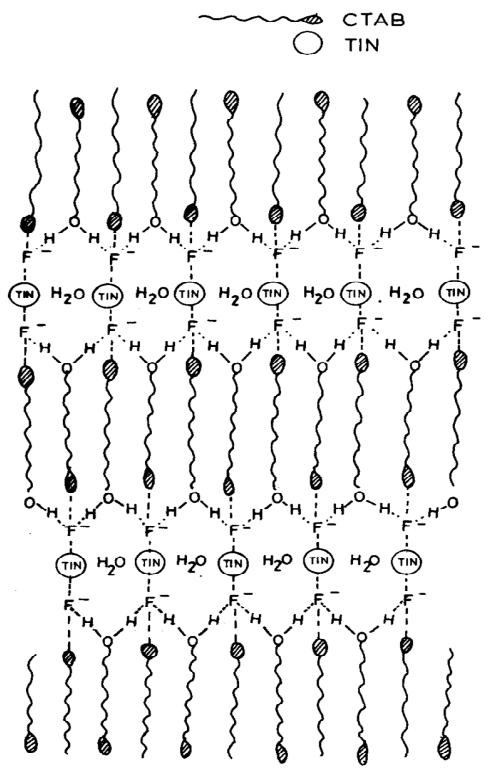

Figure 7. The mechanism underlying the synthesis of mesolamellar composite of titanium nitride and $\mathrm{CTAB}$ in the medium enriched with $\mathrm{F}^{-}$ions.

interdigitation of the surfactant tails allows the surfactant headgroups to be spaced well apart. The above lamellar composite has resulted in the formation of anatase form of titania upon heat treatment at $335^{\circ} \mathrm{C}$ for $1 \mathrm{~h}$ with the average particle size less than $10 \mathrm{~nm}$.

\section{ACKNOWLEDGEMENTS}

The support of the Council for Scientific \& Industrial Research (India) to T. V. Anuradha through a Senior Research Fellowship is gratefully acknowledged.

\section{REFERENCES}

[1] Huang, Y. and Sachtler, W.M.H. (1997) Preparation of mesostructured lamellar zirconia. Chemistry Communication, 1181-1182.

[2] Tanev, P.T. and Pinnavaia, T.J. (1996) Biomimetic templating of porous lamellar silicas by vesicular surfactant assemblies. Science, 271(5253), 1267-1269.

[3] Fernado Henrique, P.S. and Pastore, H.O. (1996) Chemistry Communication, 7, 833-835.

[4] Feng, P., Xia, Y., Feng, J., Bu, X. and Stucky, G.D. (1997) Synthesis and characterization of mesostructured aluminophosphates using the fluoride route. Chemistry Communication, 949-950.

[5] Luan, Z., Zhao, D., He, H., Klinowski, J. and Kevan, L. (1998) Tubular aluminophosphate mesoporous materials containing framework silicon, vanadium and Manganese. Journal of Physics and Chemistry B., 102(20), 12501259.

[6] Kimura, T., Sugahara, Y. and Kuroda, K. (1999) Synthesis and characterization of lamellar and hexagonal mesostructured aluminophosphates using alkyltrimethylammonium cations as structure directing agents. Chemical Materials, 11, 508-518.

[7] Froba, M. and Tiemann, M. (1998) Chemical Materials, 10(11), 3475-3483.

[8] Sayari, A., Moudrakovski, I., Reddy, J.S., Rateliffe, C.I., Ripmeester, J.A. and Preston, K.F. (1996) Chemical Materials, 8, 2080.

[9] Tiemann, M., Schulz, M., Jager, C. and Froba, M. (2001) Mesoporous aluminophosphate molecular sieves synthesised under non-aqueous conditions. Chemical Materials, 13(9), 2885-2891.

[10] Kaskel, S. and Schlichte, K. (2001) Porous silicon nitride as a superbase catalyst, Journal of Catalysis, 201, 270-274.

[11] Kaskel, S., Farrusseng, D. and Schlichte, K. (2000) Synthesis of mesoporous silicon imido nitride with high surface area and narrow pore size distribution. Chemistry Communication, 2481-2482.

[12] Anuradha, T.V. and Ranganathan, S. (1999) A comparison of the efficiency of three different synthetic routes viz. sol-gel method involving templating, mechanochemical synthesis and combustion synthesis for the production of nanostructured $\mathrm{TiO}_{2}$. Nanostructured $M a$ terials, 12, 1063-1073.

[13] Anuradha, T.V. and Ranganathan, S. (2000) Proceedings of International Symposium on Amorphous and Nanocrystalline Materials (Satellite Meeting of NANO-2000), Inoue, A., Ed., Japan Society for the Promotion of Science, 1.

[14] Tolbert, S.H., Sieger, P., Stucky, G.D., Aubin, S.M.J., Wu, C-.C. and Hendrickson, D.N. (1997) Control of inorganic layer thickness in self-assembled iron oxide/surfa- ctant composites. Journal of American Chemical Society, 119(37), 8652-8661. 
[15] Lin, W., Pang, W., Sun, J. and Shen, J. (1999) Lamellar $\mathrm{TiO}_{2}$ mesophase with an unusual room temperature photoluminescence. Journal of Material Chemistry, 9, 641-642.

[16] Beck, J.S., Vartuli, J.C., Roth, W.J., Leonowicz, M.E., Kresge, C.T., Schmitt, K.D., Chu, C.T.-W., Olson, D.H., Sheppared, E.W., McCullen, S.B., Higgins, J.B. and Schlenker, J.L. (1992) Journal of American Chemical Society, 114(27), 10834-10843.

[17] Tanev, P.T. and Pinnavaia, T.J. (1995) A neutral templating route to mesoporous molecular sieves. Science, 267(5199), 865-867.

[18] Gao, Q., Chen, J., Xu, R. and Yue, Y. (1997) Chemistry of Materials, 9, 457-462.
[19] Tiemann, M., Froba, M., Rapp, G. and Funari, S.S. (2000) Nonaqueous synthesis of mesostructured aluminophosphate/surfactant composites: synthesis, characterization, and in-situ SAXS studies. Chemistry of Materials, 12(207), 1342-1348.

[20] Huo, Q., Margolese, D.I., Ciesla, U., Demuth, D.G., Feng, P., Gier, T.E., Sieger, P., Firouzi, A., Chmelka, B.F., Schuth, F. and Stucky, G.D. (1994) Chemistry of Materials, 6(8), 1176-1191.

[21] Zhang, H. and Banfield, J.F. (1998) Size dependence of the kinetic rate constant for phase transformation in $\mathrm{TiO}_{2}$ nanoparticles. Journal of Material Chemistry, 8, 20732076. 